\title{
Building of Social Capital among Workers in Project Teams and Its Effect on Knowledge Sharing: a Saudi Arabia's Cultural Context
}

\author{
${ }^{1}$ Aljohani Amer Helail F, ${ }^{2}$ Wu Lei \\ ${ }^{1,2}$ School of Economics and Business Administration, Huazhong Normal \\ University, Wuhan, China
}

\begin{abstract}
In the study, we aim to explain how higher levels of knowledge sharing between project workers are attained by companies. The paper creates a research model that ties social capital aspects to tacit knowledge sharing. In that way, the paper suggests on what companies should focus in order to secure a higher team or firm performance through improved knowledge sharing. Social ties, trust, shared vision, reciprocity and shared language are identified as the specific social factors that are key when it comes to achieving satisfactory levels of tacit knowledge sharing. Additionally, we explore how knowledge sharing process is facilitated through Saudi Arabia network system rooted in national culture. The study is designed to suggest ways for organizations to enhance their tacit knowledge sharing. The paper employs a literature review methodology and contributes to the theory of knowledge management and organizational behavior.
\end{abstract}

Keywords: Knowledge sharing, Tacit knowledge sharing, Social capital, Saudi Arabia, Wasta

\section{INTRODUCTION}

Knowledge sharing and knowledge quality have proved to be beneficial for numerous organizational outcomes such as enhanced organizational performance and improved employee well-being (Hutching, 2006). The impact of knowledge sharing on team performance, competitive advantage, enhanced knowledge base, and innovation has been widely recorded in literature (Yui, 2002, Shih, 2006) The Organizational Citizenship Behaviour is explained by taking a significant amount of interest to daily operations of the enterprise that is not included in the day to day tasks of the employee. In other words, it involves self-commitment from the side of an employee. It can be shown in the form of helping others and cooperating with co-workers. It is also believed to be beneficial regarding collecting and sharing necessary information with co-workers.

However, in recent years, the use of IT systems has changed the situation regarding information collection, storing, processing and use. Nowadays, the role of information technologies can be seen both in explicit and implicit knowledge sharing process. Particularly, the importance of IT in tacit knowledge sharing can be viewed from three different approaches (Nahas, 1995). For example, as an expert finder, IT systems allow users to find the source of knowledge through automated systems. IT can also be important in terms of socializing of a large number of people and team members by enabling them to attach and share documents from long distance, conducting meetings and video conferences. Also, the content of the shared knowledge is kept strictly secret and can be accessed only by group members. Nevertheless, generating valuable knowledge from such information has remained a challenge (Kamara, 2002). For the purpose of exploring a behavior which we find the key to various organizational outcomes, we decided to conduct a study on this topic. We will identify social capital aspects enabling individual knowledge sharing in project teams, given that the social context is key to facilitating tacit knowledge sharing. The study 
planned aims to fill the existing gaps in theory and provide recommendations for the practice on how to attain higher tacit knowledge sharing and quality.

The problems that our study will address include the inappropriate focus of companies when they choose information technology as a tool for achieving increased creation and management of information and knowledge. Even though IT expert systems may be beneficial for data management, they presumably do not address a real need for knowledge generation. In the same way, they fail to fulfill the purpose of knowledge management as a field. Through knowing which factors, besides IT are most valuable for high knowledge performance, companies will be able to allocate their resources and efforts better in promoting knowledge management initiatives. Top management of companies will know exactly which aspect of their business they should invest in order to boost performance. Also, the study aims to fill a gap in research on social factors impacting tacit knowledge sharing modeled as a set of specific indicators in the context of Arabic business environment. We will connect key factors belonging to the organizational team context. In contrast, most of the prior studies focus on wide organizational aspects, thus ignoring an important fact that knowledge sharing, tacit in particular, is a socially conditioned behavior, which requires more focus to be put on the research of social capital.

\section{UNDERSTANDING THE NETWORK SYSTEMS IN ARABIC CULTURES}

Nowadays, many businesses are going international. There is an increasing need for international managers to become familiar with the background of cultures where their companies operate. Knowledge of the traditions and cultural prospects of the nation allows managers to establish and maintain close contacts and manage people of the organization. It is important for the businesses to establish good connections (Marzana et al. 2010) as well. For example, in China, the term known as Guanxi is described as networks, connections, and contacts. In the Arab world, the term Wasta is used to describe social connections. Therefore, analysis of social networks is considered to be useful in understanding the different cultures of the various countries such as Arab and China. Social networks are defined as a particular combination of contacts among defined set of people. Therefore, the behavior of the individuals stems from the characteristics of those involved in the group. Social network consists of the links between people who come from the same background and share similar cultural values. The importance of organization and interaction among people within these groups can be considered as the key aspect of social networks (Kamara, 2002). The existence of social networks is believed to help different individual problems without the formal presence of institutions. For example, when Chinese people face any issues related to the trade of goods, they are more likely to approach their guanxi to receive some assistance. Guanxi is considered as the interpersonal connection. However, to be successful in the business world, it is crucial to establish intercompany relationships. Due to the extended period required to develop and maintain contacts with business partners in China, it is difficult for a foreigner to get the trust of their Chinese partners since Chinese people prefer doing business with people from their guanxi. Similarly, the process of contact establishing in the Arab world is also regarded to be very time consuming (Michailova 2003). Wasta connections of Arab people are strongly related to their families and relationship ties. Wasta can also be classified as being good and bad. Wasta denoted Arab connections and was used in the form of mediation (Nahas,1995). Particularly, the head of Arab families conducted wasta services. However, recent years the term wasta has been described as the process of seeking benefit from the government. It is said that relationship of trust is known to be crucial in the Arab world. Except relying on formal agreements, Arab people mainly believe in the word of honor in business activities (Forster, 2000). This practice has significant implications concerning knowledge sharing. It can be stated that based on the social network practices of Arab people, they are more likely to share knowledge with those people whom they mainly trust and whom they have been doing business together for a long period of time. However, in terms of 
doing business with foreigners, it is tough. In this case, Arabs show high levels of individualism rather than collectivism in their behavior. Arabs believe that knowledge can be shared only if it brings benefit to the individual. Therefore, formulating a close relationship with Arab people while doing business can bring huge respect and power for the individual if they can deserve the trust of Arab people.

\section{REVIEW OF LITERATURE AND HYPOTHESIS DEVELOPMENT}

Through a comprehensive literature review, certain factors have surfaced as being conducive to tacit knowledge sharing and knowledge quality. Tacit knowledge sharing and knowledge quality are potentially impacted by various organizational factors. Social capital, management support, types of leadership, culture, climate, individual characteristics of employees, team dynamics are the key factors identified in the literature to have an impact on knowledge sharing.

Table 1: Construct concept definitions

\begin{tabular}{|l|l|}
\hline DEPENDENT VARIABLES & \multicolumn{1}{|c|}{ CONCEPT DEFINITION } \\
\hline Tacit knowledge sharing & $\begin{array}{l}\text { Knowledge that is hard to transfer to another } \\
\text { person through writing and verbalizing (Hutching, } \\
2006)\end{array}$ \\
\hline Knowledge quality & $\begin{array}{l}\text { Quality of facts, information, and skills acquired by } \\
\text { a person through experience or education (Kamara, } \\
2002 \text { ) }\end{array}$ \\
\hline Expressive ties & Close friends(Hutching, 2006) \\
\hline Instrumental ties & $\begin{array}{l}\text { People with different background, culture and social } \\
\text { background(Skok, 2010) }\end{array}$ \\
\hline Trust in co-workers & $\begin{array}{l}\text { Combination of particular beliefs mainly concerned } \\
\text { with integrity and benevolence Gerhart (2008). }\end{array}$ \\
\hline Shared language & $\begin{array}{l}\text { Specific acronyms and subtitles that are strictly } \\
\text { stipulated to day to day interactions among } \\
\text { employees of particular organization(Michailova } \\
2003)\end{array}$ \\
\hline Shared vision & $\begin{array}{l}\text { Collection of goals and aspirations which are } \\
\text { relevant to the employees of an organization } \\
\text { (Kamara, 2002) }\end{array}$ \\
\hline Identification & $\begin{array}{l}\text { One is conception of self about defining features of } \\
\text { self-inclusive social category(Nahas, 1995) }\end{array}$ \\
\hline Reciprocity & $\begin{array}{l}\text { People are more likely to share their knowledge in } \\
\text { expectation of the good and positive reward } \\
\text { (Marzana et al. 2010) }\end{array}$ \\
\hline
\end{tabular}

\section{Reciprocity}

Reciprocity in the context of knowledge sharing indicates that people are more likely to share their knowledge in expectation of the good and positive reward. Similarly, the social exchange theory can be used to explain the reciprocity more in detail (Marzana et al. 2010). That is to say that people will share their valuable knowledge only when they are sure that there will be a positive reward for them. In other words, social exchange theory can be regarded as the foundation of mutual reciprocity. Mutual reciprocity is considered as the driving force of knowledge sharing. Mutual reciprocity involves sharing knowledge with one's friends, work colleagues and expect something valuable in return. Therefore, most studies found a positive relationship between knowledge sharing and reciprocity. It is believed that mutual reciprocity is about mainly cost- 
benefit analysis. First of all, the knowledge sharing person assesses the capabilities and skills of the receiver (Forster, 2000). If he becomes sure that he will receive the positive behavior in response to his performance, he is more likely to share his knowledge. On the other hand, if it is clear that there is no chance of proper manner from the side of the receiver, the knowledge sharer does not act in his best interest.

\section{Hypothesis 1: Reciprocity has a positive impact on tacit knowledge sharing}

\section{Shared vision}

A shared vision is described as a collection of goals and aspirations, which are relevant to the employees of an organization (Kamara, 2002). Many studies describe the shared vision as a particular type of machine that can be used to perform the task of gathering different parts, ideas from several departments and resources that can be used to create value for the organization (Triandis, 2002). The people involved in the process of shared vision are more prone to share their ideas and resources with each other. In the case of virtual communities, shared vision involves all people who are common in terms of their goals and interests. Researchers suggest that knowledge sharing is vital to the success of the firm since through this process people within the organization will share their ideas, resources, and experience with each other (Hutching, 2006). As a result of shared knowledge through the process of shared vision, the quality of the shared knowledge is also likely to improve.

\section{Hypothesis 2: Shared Vision has a positive impact on tacit knowledge sharing}

\section{Shared language}

Shared language is considered to be more than compared to simple language itself. Particularly, shared language also refers to specific acronyms and subtitles that are strictly stipulated to day to day interactions among employees of the particular organization. Researchers stated that exchange of intellectual capitals is influenced in several ways due to the presence of shared language. Intellectual capital includes several types of resources, capabilities, knowledge and specific skills that are observed in employees. The higher the levels of intellectual capital, the higher the chances of the quality of knowledge shared among the employees of the organization (Michailova 2003). Many studies have focused on the importance of shared language while transmitting tacit knowledge. Unlike explicit knowledge, implicit knowledge is reported to be difficult to share through just writing or drawing. Therefore, shared language is used to build a specific set of acronyms, words, and symbols that facilitate the smooth flow of knowledge sharing process (Nahas, 1995). Moreover, shared language is not only beneficial in terms of sharing specific ideas, but it is considered to be vital for the communication process with the people who have the same background or practical experience. Furthermore, shared language is regarded as a motivating factor of quality knowledge sharing.

\section{Hypothesis 3 Shared language has a positive impact on tacit knowledge sharing}

Identification is described as "one's conception of self in terms of defining features of self-inclusive social category" (Nahas, 1995). Researchers also defined the identification as the process of observing yourself as the one person with another colleagues and workers in the organization. Moreover, identification determines one's sense of belonging and positive feeling towards an organization. Identification has also been linked to an emotional identification. In this regard, emotional identification is used to motivate the sense of loyalty and responsibility in the teamwork. Identification is also crucial to maintain a healthy and sustainable relationship with other group members (Forster, 2000). The role of identification is inevitable in tacit knowledge sharing as well. Many researchers have focused on the downside of identification which can act as a barrier while sharing a specific type of knowledge. When employees within a specific organization see others as an identity, they are more prone to share their knowledge with these people, given the similarity 
Aljohani Amer Helail F, Wu Lei

Building of Social Capital among Workers in Project Teams and Its Effect on Knowledge Sharing: a

Saudi Arabia's Cultural Context

between their goals and interests. Identification is important in defining the role of each team member within a group.

Hypothesis 4: Identification has a positive impact on tacit knowledge sharing

\section{Expressive ties}

According to social network theory, relationships can be divided into two categories (Hutching, 2006). These are expressive and instrumental ties. By literature, friendship is considered as an important part of expressive ties. The chances are that people are more likely to have expressive ties mainly with those individuals who are friends with them or those who helped those (Triandis, 2002). The people who are friend with each other are more likely to be similar in based on their social background, cultural background and character. Therefore, they have similar opinion and ideas regarding different problems given that their expressive ties are strong (Michailova 2003). Expressive ties are reported to have an active link with tacit knowledge sharing. It is true that people are more likely to share knowledge with those who have strong expressive ties with them. Moreover, the role of trust is quite important in this process. Nonaka and Tekeuchi (1995) mentioned that trust among employees is crucial to the success of the organizations resulting in the high-quality knowledge sharing the process. The current study found a positive correlation between interpersonal trust and knowledge sharing. It has been reported that the employees are more likely to feel trustworthy given that high level of honesty and reliability of recipients.

\section{Hypothesis 5: Expressive ties have a positive impact on tacit knowledge sharing}

\section{Instrumental ties}

Instrumental ties are one of the categories of social network theory alongside with expressive ties. Instrumental ties are believed to originate and be cultivated from the organizational environment and relationship with employees (Skok, 2010). Especially, people with different cultural and social background are also believed to formulate the instrumental ties. While working within one organization, employees are reported to build trust to each other (Forster, 2000). Trust is considered to be important in knowledge sharing process. People who have a trust on their coworkers and work colleagues are more likely to share tacit knowledge. The importance of confidence or trust is also essential for creating better knowledge sharing the atmosphere. Precisely, it is quite complicated to assess the level of contributed knowledge by each member of the team.

\section{Hypothesis 6: Instrumental ties have a positive impact on tacit knowledge sharing}

\section{Trust in co-workers}

The management literature describes the trust as the combination of particular beliefs mainly concerned with integrity and benevolence. Many studies define the trust as an individual belief or expectation that involves the other members of the society to observe the accepted principles. Trust has also been considered as the main antecedent in team performance of information systems members. Moreover, the crucial role of trust has been identified in the exchange of intellectual capital, the creation of organizational value, and online transactions Gerhart (2008). It has been proved by several studies that when people trust each other, precisely, when there is a high level of willingness of society members to accept and follow accepted community rules and principles, the chances of success of cooperative interactions are believed to increase. Moreover, the importance of trust is also essential for creating better knowledge sharing atmosphere (Nahas, 1995). Precisely, it is quite complicated to assess the level of contributed knowledge by each member of the team. Therefore, the importance of trust has become even more important in knowledge sharing the process of online communities as well as offline. Trust is believed in formulating good quality knowledge sharing process. 
Aljohani Amer Helail F, Wu Lei

Building of Social Capital among Workers in Project Teams and Its Effect on Knowledge Sharing: a

Saudi Arabia's Cultural Context

Hypothesis 7: Trust in co-workers has a positive impact on tacit knowledge sharing

Social capital variables Moderating effect Outcome

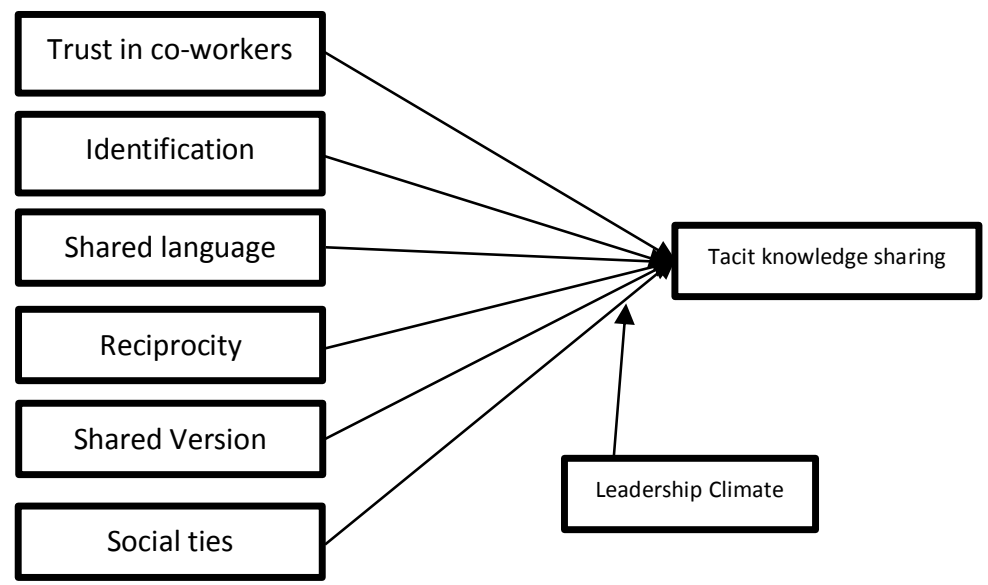

Figure 1: Proposed Tacit knowledge sharing research framework

\section{DISCUSSION AND IMPLICATIONS}

Through analysis of factors contributing to knowledge sharing of Saudi Arabia's organizations, we have developed a research framework that may be used in companies to facilitate knowledge sharing. Determining the relationships between specific social capital factors and knowledge sharing gives a new insight into a novel context of Saudi Arabian firms. The networks that exist in Arabic society guide and shape the social customs and interactions between personal, as well as business levels. Even though, such state is frowned upon in some cultures, the concept of "that facilitates daily interactions, as well as business", can be utilized and cultivated to ensure higher levels of knowledge sharing. The following relationships have been proposed based on the build model 1) Reciprocity has a positive impact on tacit knowledge sharing. 2) A shared vision has a positive impact on tacit knowledge sharing. 3) Shared language has a positive impact on tacit knowledge sharing 4) Identification has a positive impact on tacit knowledge sharing 5) Expressive ties have a positive impact on tacit knowledge sharing 6) Instrumental ties have a positive impact on tacit knowledge sharing 7) Trust in co-workers has a positive impact on tacit knowledge sharing.

In today's business operations, the management of knowledge is considered as one of the essential forces. It is believed that management of knowledge can influence the activities of the company directly and indirectly. Some of these impacts can be seen in terms of increasing rates of return on investment, satisfaction of employees. It is said that knowledge came as the only valuable resource that can enhance in its worth overtime. Therefore, it takes a lot of time and effort to manage the knowledge. Nowadays many organizations including businesses are focusing on changing their paradigm related to knowledge. That is to say they are changing the old view of the work environment to the new place where employees can work, socialize, at the same time exchange the necessary knowledge that may be useful for the business in the future. Therefore, it is possible for today's employees to take challenges and make important decisions based on the previously acquired knowledge and experience. Consequently, organizations will also benefit from the process of knowledge sharing such as reduced rates of defects in production and increase profits. Therefore, it is considered to make more investment in knowledge management within organizations. 


\author{
Aljohani Amer Helail F, Wu Lei \\ Building of Social Capital among Workers in Project Teams and Its Effect on Knowledge Sharing: a \\ Saudi Arabia's Cultural Context
}

There are different examples of companies that heavily invest in knowledge management including Xerox, IBM, and Mitsubishi. Knowledge management can also be described as the process of finding, choosing and sharing information that is relevant for organizational purposes. Particularly, knowledge sharing is considered as the key element in businesses in this century. Moreover, knowledge sharing is not expected to produce expected outcomes. In other words, there are some ways of knowledge sharing among employees that may influence negatively on the process of efficiency and productivity. In literature, two types of knowledge including explicit and implicit are thoroughly discussed. While there is a possibility of explicit knowledge to be shared easily within the organization through different means, it is quite difficult for implicit knowledge to be shared among employees. The process of knowledge sharing is based on the social theory. The social theory is also a cornerstone of social exchange and social cognitive theories. Precisely, social cognitive theories are related to human behavior. That is to say, every human before sharing his knowledge may take into account the environment, social networks, and one' personal goals. However, social exchange theory implies that people act and behave based on the output that they receive from the people surrounding them. Reciprocity, shared vision, shared language, identification, and trust have been reported to have a positive relationship with the tacit knowledge.

The process of knowledge sharing is proposed to have a number of managerial implications. First of all, sharing knowledge is quite important process that is vital for ensuring the success of organizational environment. Moreover, knowledge sharing is the main tool for fostering innovation in organization. Managers can benefit from this process in a different way. Knowledge sharing is believed to increase the mutual respect among employees as a result of trust, shared vision, share language, identification and etc.

\title{
5. CONCLUSION AND FUTURE STUDIES
}

The current conceptual study focused on explaining the link between factors and specific indicators of knowledge sharing taking an organizational and team factor view. A research model, consisting of social ties, vision, language as independent variables and tacit knowledge sharing as a dependent was constructed to solve the current problems of Organizational Citizenship Behaviour and Knowledge sharing, in Arabic societies which base his social interaction and business mainly on the concept in particular. When it comes to future studies, and empirical research in the context of Saudi Arabia should measure the performances of the factors leading to tacit knowledge sharing conceptualized through various variables which we have identified as being true indicators of knowledge sharing behavior. The results of the empirical study would provide various benefits; such as value of each factor for knowledge sharing will be identified, the mechanism of attaining higher knowledge sharing will be developed, and detailed description of Saudi Arabian firms' performance and operations will be provided.

\section{REFERENCES}

- Feld SL, Suitor JJ, Hoegh JG (2007) Describing Changes in Personal Networks over Time. Field Methods 19: 218-236, CrossRef

- Forster, N. (2000), "Expatriates and the impact of cross-cultural training", Human Resource Management Journal, Vol 10, No 3, pp. 63-78, CrossRef

- Gerhart B (2008) how much does national culture constrain organizational culture. Manage and Organization Rev 5: 241-259, CrossRef

- Hsu, I. (2006), "Enhancing employee tendencies to share knowledge - case studies of nine companies in Taiwan", International Journal of Information Management, Vol. 26 No. 4, pp. 326-338, CrossRef 


\section{Aljohani Amer Helail F, Wu Lei}

Building of Social Capital among Workers in Project Teams and Its Effect on Knowledge Sharing: a

Saudi Arabia's Cultural Context

- Hutchings, K. \& Michailova, S. (2006), "Impacts of Culture and Institutions on Knowledge Sharing in Russia and China", International Journal of Emerging Markets, Vol 1 No 1 , pp.21-34, CrossRef

- J.M. Kamara, G. Augenbroe, C.J. Anumba, P.M. Carrillo, (2002) Knowledge management in the architecture, engineering and construction industry, Construction Innovation 2 53-67, CrossRef, CrossRef

- Marzana, A. Jabar, F. Sidi and M.H. Selamat, (2010). Tacit knowledge codification. J. Comput. Sci., 6

- Michailova, S., \& Worm, V. (2003), "Personal networking in Russia and China: Blat and guanxi", European Management Journal, Vol 21, No 4, pp. 509-519, CrossRef

- Nahas, F.V., Ritchie, J.B., Dyer, W.G. \& Nakashian, S. (1995), The internal dynamics of Palestinian family business, Proceedings of Third Arab Management Conference, University of Bradford Management Centre, Bradford.

- Obrenovic, B., Jalilov, Sh (2014) Building a better national innovation system through effective knowledge sharing A case of CroatiaInternational Journal of Management Science and Business Administration Volume 1, Issue 1, December 2014, Pages $41-51$

- Shih, M., Tsai, H., Wu, C. and Lu, C. (2006), "A holistic knowledge sharing framework in high-tech firms: game and co-opetition perspectives", International Journal of Technology Management, Vol. 36 No. 4, pp. 354-67, CrossRef

- Skok W, Tahir SF (2010) Developing a knowledge management strategy for the Arab world. Electronic Journal of Information Systems in Developing Countries 41: 1-11.

- Triandis, H.C. (2002), "Generic individualism and collectivism", In The Blackwell Handbook of Cross-Cultural Management, Ed. M. Gannon and K. Newman, Blackwell, Oxford, pp. 1651.

- Ullah A, Ahmed M, Dmitry V. Zhukov (2016), Achieving Service Innovation Through Market Orientation: The Role of Relationship Marketing and Knowledge Management. International Journal of Management Science and Business Administration Volume 2, Issue 2, January Pages $19-28$

- Yiu, D. and Lin, J. (2002), "Sharing tacit knowledge in Asia", KM Review, Vol. 5 No. 3, pp. 10-11. Joint reward system 293. 